\title{
Las vidrieras del taller zaragozano La Venecia- na en Castilla y León. Sus obras en Salamanca y Zamora
}

\author{
Álvaro ÁVILA DE LA TORRE \\ Universidad de Salamanca
}

\begin{abstract}
RESUMEN. La fábrica de vidrieras La Veneciana fue la más importante de Zaragoza a principios del siglo XX. Naturalmente hay amplia muestra de su trabajo en la capital aragonesa pero su éxito y la calidad de sus obras permitieron una gran difusión. A pesar de ello, aún son bastante desconocidos los vitrales que realizaron en otras ciudades y regiones españolas, entre ellas Castilla y León. Con este artículo se pretende ofrecer una primera aproximación a los que hallamos en esa comunidad, iniciando su estudio con las encargadas para Salamanca y Zamora. La razón de esta elección es su número y su variedad estilística y temática.

Palabras clave: vidrieras, siglo XX, La Veneciana, Salamanca, Zamora.
\end{abstract}

ABSTRACT. The stained glass factory La Veneciana was the most important in Zaragoza at the beginning of the $20^{\text {th }}$ century. Obviously there is a wide repertory of its work in the capital of Aragon, but its success and the quality of its pieces allowed a great diffusion. Despite of it, the stained glasses La Veneciana made for other Spanish towns and regions, among them Castilla y León, are still quite unknown. With this article we want to offer a first approaching to those that we can find in that community, starting its study for those asked from both Salamanca and Zamora. The reason for this decision is their quantity and their stylistic and thematic variety.

Key words: stained glasses $20^{\text {th }}$ Century, La Veneciana, Salamanca, Zamora.

El presente artículo quiere ser una primera aproximación al trabajo en Castilla y León del taller vidriero zaragozano $L a$ Veneciana. Como veremos, aunque era una firma aragonesa, hay ejemplos de su trabajo por toda España. Nuestra voluntad es realizar una investigación a nivel regional. Aquí, a modo de introducción a la variedad de tipologías en la que encontramos y a la diversidad de estilos que dominó dicha empresa, ofrecemos un análisis de las muestras que se conservan en dos de los territorios de la Meseta Norte donde más presencia tuvo, las provincias de Salamanca y Zamora.

Tras la edad de oro que vivió la vidriera en nuestro país durante la Baja Edad Media y el Renacimiento, atravesó un período de crisis que se extendió desde mediados del siglo XVI hasta bien avanzada la centuria decimonónica. Fue precisamente entonces, gracias a la coincidencia de una suerte de circunstancias, cuando los vitrales recuperaron el esplendor perdido y amplia- 
ron su presencia en tipologías arquitectónicas antes insospechadas ${ }^{1}$.

Una de las causas de ese revival fue la restauración de los edificios medievales, especialmente los góticos, en los que desde muy temprano se subrayó la importancia que las piezas de vidrio polícromo tenían en ellos. Una buena muestra son las palabras de Antoni Rigalt i Blanch (1861-1914), quien tituló su discurso de ingreso a la Academia de las Ciencias y Artes de Barcelona «Las vidrieras de colores en la decoración del templo cristiano» ${ }^{2}$.

En la misma línea, otro de los elementos que permitieron el renacimiento de la vidriera en la segunda mitad del siglo XIX, en consonancia con los convencionalismos de la época que consideraban que a ciertas tipologías les correspondían determinados lenguajes arquitectónicos, fue la identificación del Gótico como el estilo más genuinamente cristiano, lo que facilitó su elección a la hora de diseñar templos $\mathrm{y}$ otras construcciones religiosas. Consecuentemente, la arquitectura neogótica contó con un inusitado desarrollo en España a lo largo de ese período, y en todos los ejemplos los ventanales protegidos por cristales de colores fueron un componente consustancial a los edificios.

Por último, el auge de la vidriera en el arco cronológico que hemos acotado también hay que ponerlo en relación con el protagonismo que adquirieron las artes decorativas, que comenzaron a ser valoradas per se, desmarcándose de cualquier dependencia. Específicamente, el vitral se liberó de su connotación exclusivamente religiosa, lo que abrió la puerta a su apari-

\footnotetext{
1 Como monografía sobre la vidriera española, vid., V. NiETO AlCAIDE, La vidriera española. Ocho siglos de luz, Madrid, 1998.

${ }^{2}$ Recogido por J. VILA GRAU y F. RONDÓN, Las vidrieras modernistas catalanas, Barcelona, 1983.
}

ción en una gran diversidad de construcciones. Especialmente llamativo fue el caso de la vivienda pues, como señaló en 1906 Juan Bautista Lázaro (1849-1919, titulado en 1874) al ingresar en la Academia de San Fernando: La moderna vidriera llamada de interior o de habitación empieza a estar en favor y tiene muy entusiastas propagadores. No son baladíes los argumentos que se emplean para demostrar su conveniencia y utilidad, aparte del placer que pueda producir su belleza, porque, en efecto, dentro de nuestras habitaciones, suele ser necesario muchas veces velar la fuerza del sol, substraerse a indiscretas miradas $y$, sobre todo, sustituir a unos vidrios incoloros. Asimismo fue novedosa su presencia en la arquitectura pública $\mathrm{y}$, en la misma línea, el citado arquitecto añadió: También en los edificios públicos tienen aplicación, y en las escuelas y cátedras se pintan mapas, colecciones de Historia Natural, máquinas y talleres, monumentos, retratos, orlas de cintas entrelazadas, en que se escriben fechas y nombres célebres, figuras alegóricas de las ciencias, de las artes, del derecho, de la filosofía, y en cuyas manos, o sirviendo de orlas, o aplicadas en cartelas, se leen máximas, axiomas y otras apropiadas inscripciones (...). En otros edificios, como sucede en las Casas Consistoriales, Diputaciones provinciales, Bancos, Casinos y otros muchos más, se aplican en los vanos de las galerías, vestíbulos, escaleras y techos, de suerte que la demanda es grande $y$ tiende a ser considerable ${ }^{3}$.

Fue en la edilicia en la que, con más precisión, la vidriera concordó con una de las principales transformaciones sufridas por la arquitectura de la época, la libertad de estilo. De este modo, hicieron su aparición los vitrales eclécticos, modernistas ${ }^{4} \mathrm{y}$,

${ }^{3}$ J. B. LÁZARO, Las artes decorativas españolas, Madrid, 1906, pp. 23-25.

${ }^{4}$ En este sentido, vid., J. VILA GRAU, Els vitrallers de la Barcelona modernista, Barcelona, 1982; J. VILA GRAU y F. RONDÓN, Las vidrieras..., Op. cit.; Ma C. MORALES SARO, El modernismo en Asturias, Oviedo, 1989, pp. 142- 
posteriormente, los incluidos en la estética art déco ${ }^{5}$.

Como consecuencia de lo expuesto, el catálogo de vidrieras realizadas en España durante las dos últimas centurias es, sin lugar a dudas, el más numeroso y variado de toda su historia.

Perdida la tradición, la mayor parte de los talleres que trabajaron en nuestro país en ese período fueron foráneos. Entre los más afamados hallamos franceses, como G. P. Degrant de Burdeos o Mauméjean, y también alemanes, caso de Mayer y Zettler ${ }^{6}$. De producción nacional, con una calidad y unas técnicas similares a las extranjeras, solo podemos hablar de la empresa de Antoni Rigalt.

En el ámbito aragonés hubo vitrales importados, como los que hoy presiden el Paraninfo de la Universidad de Zaragoza,

150 y V. Nieto AlCAide y Otros, Vidrieras de Madrid del modernismo al art déco, Madrid, 1996.

${ }^{5}$ V. NiETO ALCAIDE, «La vidriera art-déco en Madrid», en VV. AA., I Jornades Hispàniques d'Historia del vidre, Barcelona, 2001, pp. 141-144.

${ }^{6}$ Como sucinta bibliografía de estos talleres y $\sin$ aludir a publicaciones específicas sobre algunas de sus obras, vid., V. NiETO ALCAIDE, La vidriera..., Op. cit.; J. CAMPOS ORAMAS, «J. H. Mauméjean Hnos. La vidriera artística», Vegueta, 2, 1995-1996, pp. 209-218; Mª J. NiETO ZAPARAÍN YÁÑEZ, «Las vidrieras de Mauméjean en Burgos. Aportación a su estudio» en L. S. IGLESIAS RouCO (Coord.), Estudios de historia y arte: homenaje al profesor Alberto C. Ibáñez Pérez, Burgos, 2005, pp. 451458; P. PASTOR REY DE VIÑAS, Vidrieras del Taller Mauméjean en las colecciones de la Real Fábrica de Cristales de La Granja, Segovia, 2005; Ó. DA ROCHA ARANDA, «Los Mauméjean, una familia de maestros vidrieros franceses en España (1897-1952)», Goya, 315, 2006, pp. 355-370.

${ }^{7}$ J. VILA GRAU, «El vitraller modernista Antoni Rigalt i Blanch", Memorias de la Academia de Ciencias y Arte de Barcelona, 18, 1983, pp. 801-834 y N. GIL FARRÉ, «L'empresa de vitralls modernistes: Rigalt, Granell i cia. Aproximació», en VV. AA., I Jornades..., pp. 333340. realizados por la primera fábrica citada ${ }^{8}$, aunque la comunidad contó con dos compañías de cierta relevancia, Quintana y $L a$ Veneciana, que no pueden considerarse rivales, sino complementarias. La primera hizo un trabajo más artesanal, menos industrial y más de capricho. Fue fundada por Dámaso Quintana y su labor fue continuada por su hijo León, que también era profesor de Pintura decorativa sobre vidrio y cerámica en la Escuela de Artes y Oficios de la Ciudad del Ebro. Tanto él como su hijo Rogelio materializaron multitud de bocetos de los grandes artistas zaragozanos del momento, como Dionisio Lasuén o Ricardo Magdalena (1849-1910, titulado en 1873) ${ }^{9}$. Algunos ejemplos fueron la práctica totalidad de los faroles del Rosario de Cristal (1889) ${ }^{10}$, las

\footnotetext{
${ }^{8}$ Como aportación al conocimiento de la vidriera aragonesa de finales del siglo XIX y principios del XX, vid., M. GARCÍA GUATAS, «La vidriera contemporánea en Zaragoza», Seminario de Arte Aragonés, 48, 1999, pp. 365-400; B. ISASI-ISASMENDI, La vidriera artística en Zaragoza: Talleres Quintana y los Rosarios de Cristal, Trabajo de investigación del D.E.A., Zaragoza, 2009 (inédito) y B. ISASI-ISASMENDI, La vidriera artística contemporánea en Zaragoza, Tesis doctoral en curso, Universidad de Zaragoza.

${ }^{9}$ J. MARTíneZ VERÓN, Arquitectura aragonesa: 18851920. Ante el umbral de la modernidad, Zaragoza, 1993, p. 57. Ricardo Magdalena fue el gran protagonista de la arquitectura zaragozana a caballo entre los siglos XIX y XX. Arquitecto municipal de Zaragoza desde 1876, ocupó multitud de cargos y fue autor de un sinfín de obras en la capital aragonesa y en otras localidades, entre las que destacan las Facultades de Medicina y Ciencias (1886), la reforma de la Universidad Literaria (1900), los edificios más representativos de la Exposición Hispano-francesa de 1908, el quiosco de la música del Bulevar (1907) de San Sebastián, etc. Sobre este técnico, como estudios fundamentales, vid., A. HERNÁNDEZ MARTíneZ, Ricardo Magdalena. Cien años de historiografía sobre arquitectura aragonesa, Zaragoza, 1997 y Vida y obra del arquitecto Ricardo Magdalena (1849-1910), Zaragoza, 1999.

${ }^{10}$ En referencia a estos faroles y sus valores estéticos, vid., A. Hernández MartíneZ, «El Rosario de Cristal de Zaragoza: aspectos artísticos de una devoción religiosa» en VV. AA., Homenaje a don Antonio Durán Gudiol, Huesca, 1995, pp. 427-440. También hicieron algunas obras para otros desfiles procesiona-
} 
vidrieras del Palacio de la Capitanía General $(1893)^{11}$, las confeccionadas a raíz de las sucesivas reformas llevadas a cabo por Francisco Albiñana (1887-1936, titulado en 1911 $)^{12}$ en el Centro Mercantil, Industrial y Agrícola (1903-1920) ${ }^{13}$ y las del cine Ena Victoria (1912) ${ }^{14}$. Fuera de Zaragoza, realizaron faroles para los rosarios procesionales de Valladolid, Toledo, Vitoria, Castellón, Haro, Atienza y Sigüenza.

Por lo que respecta a La Veneciana, fue fundada en 1876 por Basilio Paraíso (1849-1930), uno de los grandes prohombres locales de la época y promotor de la Exposición Hispano-Francesa de 1908. Nació como fábrica de espejos, lucernarios y cristaleras, aunque después se diversificó y también creó vidrieras, rótulos luminosos y

les, como los de las cofradías de Semana Santa, vid. A. GARCÍA DE PASO REMÓN, «Tradición metalistera y vidriera: el taller Quintana en la Semana Santa de Zaragoza», Tercerol: cuadernos de investigación, 10, 2006, pp. 51-80.

${ }^{11}$ En referencia a este palacio, vid., J. Gómez PALLATE, El nuevo palacio de la Capitanía General de Aragón (edición facsímile), Zaragoza, 1994 y M. GARCía GuATAS, En el centenario del palacio de Capitanía General, Zaragoza, 1997.

${ }^{12}$ Natural de Zaragoza, fue presidente de la Asociación Regional de Arquitectos de Aragón, arquitectojefe de la Segunda Región del Catastro Urbano, profesor de la Escuela de Arte y Oficios de Zaragoza y concejal en el Ayuntamiento de esa ciudad. Se preocupó mucho por la vivienda obrera y diseñó multitud de inmuebles en la capital aragonesa, la mayor parte en el casco y las zonas por entonces en proceso de urbanización, como las actuales plaza de los Sitios y la calle Conde de Aranda. De cualquier manera, su obra más conocida fue el Centro Mercantil, Industrial y Agrícola (1912). (J. MARTíneZ VeróN, Arquitectos en Aragón. Diccionario histórico, Zaragoza, 2000, pp. 14-15).

${ }^{13}$ Sobre este inmueble, vid., J. MARTínEZ VERÓN, El centro mercantil, industrial y agrícola de Zaragoza (1909-1935), Zaragoza, 1985. Específicamente sobre su decoración, vid., M. GARCíA GUATAS, «Los proyectos decorativos del Mercantil», en VV. AA., Zaragoza a principios del siglo XX. El modernismo, Zaragoza, 1977, p. 55.

14 A. Martínez HerranZ, «Catálogo de cien años de cines en Zaragoza», Artigrama, 11, 1994-1995, p. 196. escaparates ${ }^{15}$. Tuvo su primera sede en la zaragozana plaza de Santa Engracia ${ }^{16} \mathrm{y}$ veintiún años más tarde, dado su tremendo éxito, se trasladó a la actual calle Doctor Cerrada, a una construcción con cierto aire neomudéjar, del arquitecto Félix Navarro Pérez (1849-1911, titulado en 1874) ${ }^{17}$. A medida que aumentó su producción comenzó a expandirse fuera de Aragón. Así, en 1923 sus propietarios abrieron una sucursal en Sevilla, dos años después en Madrid y Valencia y posteriormente en Pamplona, Murcia y Salamanca ${ }^{18}$, pero parece que los vitrales siempre se fabricaron en Zaragoza $^{19}$.

La implicación del fundador en la vida ciudadana provocó que la compañía participara en varias celebraciones locales, entre las que sobresale su presencia en la Exposición Regional Aragonesa de 1885 y, naturalmente, en la Exposición HispanoFrancesa de 1908, en la que contó con pabellón propio ${ }^{20}$.

A pesar de que la realización de vidrieras no estaba entre sus prioridades, $L a$ Veneciana fue la otra empresa responsable

-

${ }^{15}$ M ${ }^{\text {a }}$ P. BIEL IBÁÑEZ, Zaragoza y la industrialización: la arquitectura industrial en la capital aragonesa entre 1875-1936, Zaragoza, 2004, pp. 623-638.

16 J. MOVEdA PuYOL, Comerciantes de altura, Zaragoza, 1949, p. 17.

${ }^{17} \mathrm{M}^{\mathrm{a}} \mathrm{P}$. BIEL IBÁÑEZ y A. HERNÁNDEZ MARTíN, $L a$ arquitectura neomudéjar en Aragón, Zaragoza, 2005, pp. 70-71. Pertenecería, tal y como determinaron estas doctoras, a la primera fase del Neomudéjar en Aragón, que se caracterizaba por ser una arquitectura ecléctica e historicista con rasgos neomudéjares (...). Tipológicamente este estilo se asocia sobre todo a la arquitectura religiosas y asistencial, como en Madrid, también a la arquitectura industrial (Ibídem, p. 59).

${ }^{18}$ La Veneciana. Un siglo de actividad en la industria vidriera, Zaragoza, 1975.

${ }^{19}$ M. GARCÍA GUATAS, «La vidriera...», Op. cit., p. 387.

20 J. MARTÍnEZ VERÓN, Arquitectura de la Exposición Hispano-Francesa de 1908, Zaragoza, 1984, pp. 89-99. 
de la que se ha denominado como edad de oro de la vidriera contemporánea en Zarago$\mathrm{za}^{21}$, todo ello gracias a la calidad de sus dibujantes y al aumento de la demanda. Desde un punto de vista técnico su objetivo principal fue compaginar el proceso mecanizado, que permitía abaratar los precios, con un acabado de calidad. Algunos de los ejemplos más brillantes fueron los vitrales del cine Alhambra (1912) ${ }^{22}$, los del coreto de la Basílica del Pilar (1914), los del Centro Mercantil -para la sala de billares (1917) y el restaurante (1920)-, los del salón de sesiones de la Real Academia de Medicina y Cirugía (1928) y, ya en época más reciente, los de los despachos de la Jefatura Provincial de Sanidad (1935) y el farol de Santo Dominguito del Val para el Rosario de Cristal.

Poco se sabe de la obra de La Veneciana fuera de la Ciudad del Ebro. Tenemos constancia de la realización de una vidriera para la Escuela de Comercio de Gijón ${ }^{23}$, las de la capilla mayor de la Catedral de Jaén (1911), unas estrechas, de filiación modernista, para la Cámara de Comercio de Melilla (1913), otra para la escalinata del Ayuntamiento de la citada ciudad andaluza (1915), cinco más, a modo de montantes, para el Café-Bar Derby de Santiago de Compostela (1929), las de la Concatedral de Santa María de la Redonda en Logroño (1929) y las de la escalera del Consistorio de Teruel (19421944). Cerca de nuestro ámbito geográfico, hay las que decoran una claraboya (1934) y unas puertas (1936) en la casa de Josefina Fernández en La Bañeza (León).

Precisamente con el objetivo de ampliar el conocimiento de la labor de este taller y como primera aportación a un tra-

\footnotetext{
${ }^{21}$ Así la definió Manuel García Guatas (M. GARCÍA GUATAS, «La vidriera...», Op. cit., p. 385).

22 A. MARTÍNEZ HERRANZ, Op. cit., p. 190.

${ }^{23} \mathrm{M}^{\mathrm{a}}$ C. MORAlES SARO, Op. cit., p. 147.
}

bajo específico sobre la actividad vidriera de la casa zaragozana en Castilla y León, presentamos en este artículo los vitrales que La Veneciana realizó para Salamanca y Zamora.

La primera ciudad vivió un notable desarrollo arquitectónico a caballo entre los siglos XIX y XX. Era la capital de un territorio eminentemente rural que se vio parcialmente favorecida por la reactivación productiva que supuso la pérdida de las colonias y el aumento de la demanda europea $^{24}$. Asimismo, hubo una favorable evolución en los precios del cereal y de la carne y un ligero despunte de la industria de curtidos. También surgieron nuevas fábricas de energía eléctrica, La Eléctrica Salmantina y La Energía Eléctrica, y se mantuvieron otras, como la fundición Moneo Hijo y Cía., la de abonos Hijos de Mirat y dos harineras, Santa Elena y El Ángel. Socialmente, la burguesía comercial fue imponiéndose, sobre todo superada la segunda década de la pasada centuria y dentro de un proceso continuo de terciarización económica. Demográficamente, se manifestó un notabilísimo incremento debido a la inmigración provincial que supuso que en 1940 la capital triplicara su población respecto a $1900^{25}$.

A todo ello debemos sumar la labor de notables arquitectos, como Pedro Vidal Rodríguez Barba (nacido en 1855 y titulado en 1882), Joaquín de Vargas Aguirre (18551935, titulado en 1883), Santiago Madrigal Rodríguez (1878-1923, titulado en 1904), José Yárnoz Larrosa (nacido en 1884 y titulado en 1910) o Genaro de No Hernández

24 E. GONZÁlez GARCía, «Marco económicofinanciero», en VV. AA., Historia de la Caja de Ahorros y Monte de Piedad de Salamanca (1881-1981), Salamanca, 1982, p. 155.

${ }^{25}$ E. GARCíA ZARZA, Salamanca. Evolución, estructura, forma de poblamiento y otros aspectos demográficos (1900/1970), Salamanca, 1976, p. 200. 
(1894-1978, titulado en 1918) ${ }^{26}$. Todos estos elementos permitieron la modificación del tejido de la ciudad, la renovación del caserío y la construcción de notables edificios ${ }^{27}$.

Además de las vidrieras de La Veneciana, en Salamanca encontramos otras contemporáneas. Las mejores son las que realizó Mauméjean para las capillas de Nuestra Señora de la Vega, del Noviciado de los Jesuitas y del Colegio de las Esclavas del Sagrado Corazón. También citaremos las modernistas que tuvieron los montantes de las puertas y las cristaleras del patio de la Casa Lis.

Los vitrales más antiguos de la casa aragonesa en Salamanca fueron los de la tribuna de la Capilla-Panteón de los Marqueses de Castellanos. Ubicada en la avenida de los Reyes de España, está situada en el lugar en el que se hallaba el Monasterio premostratense de Santa Susana y San Norberto. Este cenobio, del que se conserva el claustro, diseñado por Juan Moreno en 1615, tras la Desamortización fue usado como establo y, tras su cesión para alojar un hospital durante la epidemia de cólera de 1885, fue otorgado en 1899 por Agustín Maldonado Carvajal, marqués de Castellanos y Monroy, a las Hijas de Jesús para que abrieran su noviciado. Una vez instaladas, las jesuitinas llevaron a cabo algunas modificaciones $\mathrm{y}$, obedeciendo las disposiciones del benefactor, tras su fallecimiento, se construyó la capilla.

El arquitecto Federico de Arias Rey firmó los planos en 1911 en Madrid ${ }^{28}$. A

\footnotetext{
${ }^{26}$ En este sentido, vid. J. I. DíEZ ElcUAZ, Arquitectura y urbanismo en Salamanca (1890-1939), Salamanca, 2003, pp. 465 y ss.

27 Ibídem.

${ }^{28}$ Federico de Arias Rey se tituló por la Escuela de Arquitectura de Barcelona. Inició su carrera en Madrid donde proyectó dos inmuebles de sesgo modernista, un edificio de viviendas para Juan Boix (1910), en la
}

pesar de ello, parece que el auténtico proyectista fue el italiano Enrique F. Daverio ${ }^{29}$, quien también dirigió las obras. Esto se debió a la necesidad de que apareciese un técnico español ${ }^{30}$. Tiene una sola nave con sótano y coro lateral elevado para las monjas. Adosado está el panteón, de planta octogonal, adornado con esculturas de la Fe, la Esperanza, la Caridad y un ángel realizados por Arturo Luchetti ${ }^{31}$. Queda integrada en un Eclecticismo de aire italianizante. La parte más interesante es la fachada. Todo el piso inferior, donde se abre la portada, es almohadillado. Encima se abren los vanos de la tribuna flanqueados por dos cuerpos, que emulan los templos griegos, coronados por ángeles. En el centro se eleva el campanario rematado por un campanil con una llamativa cúpula bulbosa. Las marcadas referencias clásicas, bizantinas e italianas, así como el gusto por la policromía, enriquecida por la presencia de azulejos de Daniel Zuloaga en el tímpano, confirman el origen transalpino del tracista.

Las tres vidrieras de La Veneciana cierran los huecos de medio punto de la tribuna. Las tres poseen una orla con una peana,

confluencia de las avenidas Ciudad de Barcelona y Menéndez Pelayo, y la notable Casa Gallardo (1911). En 1915 se trasladó a La Habana. Entre las obras diseñadas por él en la isla caribeña destaca la reforma de la Quinta Rosario (1918). (M. VILLAVERDE REY, «La cerámica aplicada en la arquitectura modernista en Cuba», en VV. AA., Tradición y modernidad: la cerámica en el modernismo, Esplugues de Llobregat, 2004, p. 2006 y Ó. DA ROCHA ARANDA, El modernismo en la arquitectura madrileña. Génesis y desarrollo de una opción ecléctica, Madrid, 2010, pp. 283 y ss.).

${ }^{29}$ Enrique Daverio Bara es un arquitecto muy desconocido, además de su intervención en Salamanca, únicamente tenemos constancia de su colaboración con Federico de Arias Rey en el diseño de la Casa Gallardo, a la que aludimos en la nota anterior.

${ }^{30}$ Archivo Municipal de Salamanca (AMS), obras, sign. 1911/96.

${ }^{31}$ J. R. NiETO GONZÁLEZ, A, «Los monumentos religiosos (siglos XVI-XX)», en VV. AA., Salamanca. Geografía. Historia. Arte, Salamanca, 1986, p. 380. 
pilastras clasicistas y un arco, que en el caso de la ventana central presenta múltiples motivos sinuosos. En las laterales se representaron sendos ángeles de perfil en adoración. Tras ellos hay una baranda y un paisaje. En el vano del medio aparece San Agustín dentro de una hornacina. Vestido de obispo, interrumpe la escritura de su célebre libro La ciudad de Dios y eleva la mirada buscando la inspiración divina. La elección del prelado africano hace referencia al nombre del marqués de Castellanos.

Los cierres vítreos fueron realizados en 1913. Estilística e iconográficamente guardan relación con el inmueble en el que están. Las formas recuerdan el Renacimiento italiano; el reducido emplomado, los marcos, las vestimentas de los ángeles y su físico juvenil, el interés por el volumen y la disposición del fondo van en esta línea.

Debemos llamar la atención sobre la calidad de los vitrales, sobre la riqueza polícroma y el interés en imitar las texturas. Además, cabe resaltar la voluntad de evitar la monotonía, pues aunque son simétricos, los dos seres angelicales son bien diferentes, en su postura, en sus alas y en los detalles de sus ropajes. Por otro lado, es loable la renuncia a imprimirles un carácter historicista, como hubiera sido lo habitual por entonces, especialmente en un templo, toda vez que desde el siglo XIX quedó establecido que el Gótico era el estilo que mejor definía la espiritualidad cristiana. Sin embargo, se buscó una premeditada armonía con el Eclecticismo clasicista de la capilla.

Desde un punto de vista técnico, hay una gran minuciosidad y detallismo en la elección de los colores del propio cristal, llamados de mufla, en la aplicación del trait, es decir, el dibujo aplicado sobre el vidrio, y especialmente del lavis, la veladura que logra el modelado, que es patente en los paisajes.
Mucho más amplio es el conjunto de vidrieras de la capilla del Hospital de los Montalvos. Este centro hospitalario se encuentra a las afueras de Salamanca y es el ejemplo más señero del Racionalismo en la ciudad. Su construcción fue favorecida por dos salmantinos, los doctores Filiberto Villalobos y Víctor Villoria. Su notoriedad fue tal que los planos del centro pudieron verse en la Exposición Universal de París de 1937. El proyecto, de 1935, fue redactado por Rafael Bergamín (1891-1971, titulado en 1918) ${ }^{32}$. Ese mismo año comenzaron las obras que, dados los acontecimientos posteriores, se prolongaron hasta 1944, y la inauguración se pospuso aún cuatro años más. Las obras fueron dirigidas por Genaro de No (1894-1978, titulado en 1918) que no varió sustancialmente el plan de su compañero de estudios ${ }^{33}$.

Sigue los esquemas en bloque de los sanatorios estadounidenses, en este caso en horizontal, con cuatro cuerpos de habitaciones separados por módulos para las enfermeras y uno central para la administración. Los cuartos de los pacientes poseen amplísimos ventanales y extensas terrazas. El objetivo, como era preceptivo en la época, era garantizar al máximo la penetración de los rayos solares y una correcta ventilación de los enfermos respiratorios que en él recibirían cura.

Tras la Posguerra se realizaron algunas modificaciones, entre ellas, se creó una

32 J. GONZÁLEZ CuBERO, «Arquitectura hospitalaria de José Bergamín: el Sanatorio de los Montalvos», en VV. AA., Arquitectura moderna en Salamanca, Salamanca, 1998, p. 37.

${ }^{33}$ El salamantino Genaro de No nació en una familia acomodada. Fue arquitecto municipal de Salamanca por unos días, pues al conseguir la titularidad en Hacienda renunció a la primera plaza. Inició su trayectoria en el Regionalismo de corte Neoplateresco y Neobarroco, pero posteriormente se embarcó en la aventura racionista (J. I. DíEZ ELCUAZ, Op. cit., pp. 475476). 
capilla. Tiene planta trapezoidal, con una sola nave y aunque hoy su presbiterio es adintelado, sabemos que inicialmente se cubrió con bóveda de cañón ${ }^{34}$. En los muros laterales están rasgados ocho ventanales de medio punto, agrupados por parejas, con vidrieras de La Veneciana. Lamentablemente no están firmadas, pero concluimos que provienen de Zaragoza porque al acto de colocación de la primera piedra del hospital, ocurrido el cinco de abril de 1935, asistió Alejandro Hernández Arroyo en representación del taller aragonés ${ }^{35}$.

Todos los vitrales tienen la misma estructura. Poseen una cenefa en zigzag y tres cuerpos. En el inferior hay un puente de tres ojos y sobre él una estrella de ocho puntas inscrita en una corona de laurel flanqueada por cruces refulgentes. En el superior hallamos una cruz patada dentro de un círculo y una estructura arquitectónica imaginaria. La parte central aloja una figura sobre un fondo neutro de emplomado irregular.

En las más cercanas al presbiterio se representaron los cuatro evangelistas. Juan y Marcos en el lado de la Epístola y Mateo y Lucas en el contrario. Todos aparecen de pie, sobre un enlosado, portan sus libros y parecen meditar. A sus pies están los correspondientes símbolos del tetramorfos. Como es habitual, Juan es más joven y quizás por ello su vestimenta es más clara. Todos están descalzos, excepto Marcos. El maestro vidriero intentó evitar la monotonía y por eso adoptan posturas diferentes, tanto en los cuerpos y en las cabezas como en las manos.

El resto de los vitrales están ocupados por ángeles femeninos que se elevan

\footnotetext{
34 Así aparece en un fotografía publicada en el diario El Adelanto, el 5 de febrero de 1950, p. 6.

${ }^{35}$ El Adelanto, 6 de abril de 1935.
}

sobre las nubes y portan atributos de Jesús y de María que, a la postre, es la titular de la capilla. En el muro de la Epístola, el primero, que cubre su cabeza, sostiene un cuadro con una flor, clara referencia al atributo mariano de Rosa mística; el segundo enseña un marco repujado con un cofre en su interior, lo que interpretamos como la letanía Arca de la Alianza. La tercera y la cuarta figuras tienen una estrella en la frente y aguantan entre sus manos un emblema con un pozo -la madre de Cristo como Pozo de sabiduría- y una palmera tras un murete. El árbol es símbolo de triunfo y aparece en múltiples cuadros de la Inmaculada Concepción, aunque la presencia de la pared podría indicar que se trata de la alusión al Hortus conclusus, al huerto cerrado. Las dos últimas llevan escudos. Uno con una custodia de la que surge una sagrada forma y otro con un jarrón. Vaso espiritual, vaso digno de honor y vaso insigne de devoción son denominaciones de las letanías.

En el lado contrario, la primera figura femenina muestra una insignia con una fuente de la que beben unos pájaros, la Virgen como Fuente sellada o como Divinae Gratiae, que la iconografía refigura como un surtidor rebosante. La segunda, que tiene un círculo que aloja un triángulo con rayos, puede referirse al carácter de Mater inviolata de María o quizás a su carácter de Madre de Dios. La tercera insignia es Stella Maris y la cuarta, con una paloma, alude a la esposa de San José como templo del Espíritu Santo. La quinta y la sexta creemos que hay que relacionarlas con Cristo. Uno de los ángeles lleva un escudo con una escalera, una lanza y una esponja, claros símbolos de la Pasión. Idea que confirma la cara llorosa del tenante. La última figura sostiene las siglas JHS.

El conjunto se completa con las cuatro vidrieras del testero de la sacristía. Son similares a las otras y en ellas se continúa el ciclo de la muerte de Cristo, una cruz con la lanza y la esponja, los tres clavos junto a la 
corona de espinas, unas tenazas y un martillo y, por último, una columna y unas fustas.

Los personajes alados difieren poco entre ellos, algunos van vestidos con dalmáticas y otros con casulla. A pesar de ello el artista evitó la monotonía al variar sus posturas, los colores y los pliegues de las túnicas, la disposición de los cabellos, la forma de las alas, la forma de los marcos de los emblemas, etc.

Iconográficamente las simbologías marianas y cristológicas son muy habituales desde el barroco. Lo que extraña en este caso es la secuencia en las que se encuentran. Creemos que los vitrales se encargaron cuando se proyectó el Hospital, recordemos que un representante de La Venecia$n a$ asistió a la colocación de la primera piedra, y al diseñar la capilla en la Posguerra no se tuvo en cuenta su número. Sería la razón de que dos con temas de la Pasión estén en la nave y cuatro restantes, del mismo contenido, se hallen en un lugar de difícil contemplación como es la sacristía.

Desde un punto de vista técnico, al haber sido confeccionadas a mediados de la pasada centuria, estas vidrieras se incluyen en el epígono del resurgir decimonónico del vitral emplomado. Poco tiempo después se impondría el de hormigón armado. Estilísticamente pertenecen a la fase final del realismo y están todavía imbuidas del espíritu historicista de las décadas precedentes, cuando se imitaba las medievales. Como en estas se reservó una orla perimetral que, en los templos góticos, dadas las irregularidades de los ventanales, sería necesario recortar en la fase de colocación. Una precaución que en los siglos XIX y XX la tecnología hacia innecesaria. Igualmente solo hay una figura en cada vano, de pie, de frente y ante un fondo neutro. Además aparecen enmarcadas como si fueran esculturas, sobre una peana y con un cuerpo superior que evoca de manera muy libre los doseletes. Por último, como pasó en las vidrieras neogóticas, la tendencia al abundante emplomado y la renuncia a la tridimensionalidad no afectaban a los personajes, en los que hay abundantes efectos de claroscuro y de volumen. El único elemento que indica una cierta modernidad y que avanza los cambios que sufrió este arte en la segunda década de la pasada centuria es la ausencia de narración y la preferencia por los temas teológicos y conceptuales.

Analizado el caso de Salamanca, pasamos al de Zamora. En este municipio hay tres conjuntos vitrales de gran interés. Por su ubicación, su temática y su cronología son dignos exponentes de la evolución de la vidriera.

Esta ciudad castellano-leonesa tuvo un esplendor espectacular desde el punto de vista arquitectónico entre 1875 y 1930. La llegada del ferrocarril en 1864, la pérdida de su condición de plaza de guerra en 1869, un cierto afloramiento económico que dio lugar a la aparición de una relativamente importante clase burguesa, la presencia en Madrid de destacados representantes políticos de esa circunscripción, como Claudio Moyano (1809-1890), Práxedes M. Sagasta (1825-1903) o Federico Requejo (1854-1915), y el trabajo de notables arquitectos, caso de Segundo Viloria (1853-1923, titulado en 1877), Gregorio Pérez Arribas (1877-1937, titulado en 1901), Antonio García SánchezBlanco (1893-1963, titulado en 1918) y sobre todo el barcelonés Francesc Ferriol (18711946, titulado en 1894), fueron elementos que, gracias a su simultaneidad, provocaron una renovación del tejido medieval del municipio y la elevación de innumerables edificios de notable factura y variada tipología ${ }^{36}$.

36 Sobre este tema, vid., Á. ÁvILA DE LA TORRE, $A r-$ 
En referencia a la vidriera, aunque nos centraremos en la obra del taller zaragozano La Veneciana, conviene indicar que también existen otras de diversa procedencia, como las de la escalera del Palacio Provincial (1867), anónimas, o las confeccionadas por Mauméjean para el Ayuntamiento diseñado en 1932 pero inaugurado en 1950o para el Palacio de Justicia (1945) ${ }^{37}$.

Las más antiguas de la casa aragonesa fueron las del camarín de Nuestra Señora del Tránsito, en la iglesia de Convento del Corpus Christi. Este cenobio fue fundado en 1597 en el solar resultante del derribo de unas casas donadas a una comunidad de Franciscanas descalzas por los Marqueses de Astorga, don Juan de Carvajal y doña Ana Osorio de Ribera ${ }^{38}$. El templo no se terminó hasta 1605, tal y como señala la lápida del enterramiento de los fundadores. Posee una sola nave con bóveda de lunetos y su fachada principal está orientada al norte. Es muy sobria, en ella se abrió una puerta adintelada y se animó con los escudos de los promotores y una hornacina que acoge una custodia flanqueada por dos ángeles. A pesar de su escaso interés artístico, es un lugar de especial cariño para los zamoranos, pues en él se venera la imagen de la Virgen del Tránsito, escultura yacente anónima, que hasta finales del siglo XIX se encontraba expuesta a la devoción de los fieles en una pequeña capilla rectangular adosada al presbiterio.

Coincidiendo con el período de desarrollo urbanístico y arquitectónico de la localidad y con el renacimiento del catoli-

quitectura y urbanismo en Zamora (1850-1950), Zamora, 2009.

37 Á. Ávila de LA TORRE, Á., Op. cit., pp. 214, 471 y 479 respectivamente.

38 M. EsPÍAs SÁNCHEZ, Monasterios de clausura de Zamora, Zamora, 1980, p. 163. cismo en toda España ${ }^{39}$, el Obispado planteó la construcción de un camarín más suntuoso, que sustituyera la cabecera de la iglesia, de factura modesta.

En 1896 fue nombrado responsable de las intervención un renombrado personaje local, el sobrestante de obras públicas y concejal Eduardo J. Pérez (titulado en 1862). Se conserva en el Archivo Diocesano un interesante álbum con un variado número de soluciones para el nuevo ábside, todas ellas historicistas, algunas cercanas al Románico y otras con imaginativas formas goticistas ${ }^{40}$. De cualquier manera, los planos definitivos, de 1897, aunque copian los confeccionados por el citado técnico, llevan la firma de Vicente Lampérez (1861-1923, titulado en 1886) ${ }^{41}$. Proponía una cabecera semicircular, con seis amplios ventanales apuntados separados por pilastras, cuyos muros remataban con una crestería abalaustrada, alternada con peanas con jarrones.

${ }^{39}$ Para profundizar en este campo, vid., M. M. CAMPOMAR FORNIElles, La cuestión religiosa en la Restauración, Santander, 1984.

${ }^{40}$ Archivo Histórico Diocesano de Zamora (AHDZa), Sección Secretaría de Cámara (SC), legajo 99, expediente 6, año 1896.

41 AHDZa, SC, legajo 99, expediente 15, año 1897. La figura de Vicente Lampérez es sobradamente conocida. Su labor más importante fue la de restaurador, interviniendo en las catedrales de León (1886), Burgos (1890-1892 y 1913) y Cuenca (1909) y en la Casa del Cordón de la capital burgalesa (1909). Entre sus proyectos privados sobresale la modernista casa de las hermanas Bohígas (1907) en la Plaza Mayor de la citada localidad castellana [P. L. GALLEGO FERNÁNDEZ, «La restauración de la Catedral de Burgos», en VV. AA., Catedrales de Castilla y León, tomo 3, Valladolid, 1996, pp. 20-32; J. J. RiverA BlANCO, Historia de las restauraciones de la Catedral de León: "Pulcra Leonina", la contradicción ensimismada, Valladolid, 1993; P. NAVASCUÉS PAlACIO, Arquitectura española (1880-1914), SUMMA ARTIS, volumen XXXV**, Madrid, 1996, pp. 378-380 y L. S. IGLESIAS ROUCO, «Aspectos modernistas en la arquitectura burgalesa, 1900-1930», Masburgo, Miscelánea de Estudios Humanísticos, 2, 1987, pp. 144 y 146]. 
A pesar de que optó por una concepción goticista, al hilo de lo que era habitual en la época para la arquitectura religiosa ${ }^{42}$, esta filiación estética fue profundamente matizada. En el interior, las formas eran más clasicistas, tal vez para armonizar con el estilo de la nave. El muro de cerramiento del camarín se adaptaba a la forma de la cabecera y estaba constituido por ocho columnas corintias, que sostenían un friso coronado por estatuas de santos, alternadas con amplios ventanales de medio punto protegidos con rejas, que permitían la contemplación de la imagen de la Virgen y, dado que no se abrían a la calle, conferirían una luz tenue muy efectista.

Al final, todo resultó más sencillo pero, para nuestro fin, interesa señalar que se intensificaron los elementos neogóticos, no sólo porque fuera desapareció la balaustrada del coronamiento y se sustituyó por pináculos, sino porque en el interior se decidió sustituir por vidrieras las protecciones férricas de las ventanas.

Esta modificación ya quedó manifestada en la descripción que publicó El Correo de Zamora el veintisiete de marzo de 1897, poco antes de comenzar las obras, donde, en referencia a la iluminación, se afirmaba: La combinación de luces por su bien estudiada disposición, será indudablemente uno de los detalles que llamarán agradablemente la atención de los fieles, pues las grandiosas ventanas del ábside de 7,5 metros de altura, recibiendo luces, también, del lado del mediodía al través de sus hermosas vidrieras de colores, su efecto ha de ser maravilloso ${ }^{43}$.

Sea como fuere, aunque la construcción de la nueva cabecera se dio por con-

${ }^{42}$ P. NAVASCUÉS PALACIO y M $M^{\mathrm{a}} \mathrm{J}$. QUESADA MARTín, El siglo XIX. Bajo el signo del Romanticismo, Madrid, 1992, pp. 43 y ss.

${ }^{43}$ El Correo de Zamora, 27 de marzo de 1897. cluida en agosto de 1899, los cinco vitrales, realizados en 1916 por La Veneciana, no se colocaron hasta ese año. Se adaptan a los vanos de medio punto y presentan una variada iconografía, en todos los casos con una orla decorada con hojas menudas y rizadas. De izquierda a derecha, en la primera ventana hallamos una abundante ornamentación vegetal simétrica distribuida en cuatro grandes cuadrifolios. En la segunda, enmarcado en la misma profusa hojarasca, se representó a San Isidoro. Está vestido de pontifical y porta un libro y un báculo. En el vano central, hay el anagrama del Ave María dentro de una circunferencia, de la que surgen rayos bicolores. Completan la escena unos rostros angelicales. Por último, los dos últimos huecos están ocupados por la figura de San José, de pie, con el Niño bajo el brazo y la vara de lirio florido $\mathrm{y}$, de nuevo, una composición de temática completamente naturalista.

Técnicamente son de una altísima calidad, las piezas del vidrio están perfectamente emplomadas, los colores de mufla son nítidos y uniformes, el lavis es suave, moderado y gradual y la grisalla consigue amplios efectos pictóricos y colabora al embellecimiento general.

Estilísticamente son piezas historicistas, que manifiestan una característica muy habitual en la época, pues hay un contraste entre la ornamentación, en la que existe una correspondencia más acertada con los modelos del pasado que se pretende evocar, y la figuración, más clasicista y académica. Las figuras aparecen sobre un fondo neutro, lo que debe interpretarse como una clara renuncia a los efectos tridimensionales. Si hubiera que clasificarlas, están más cerca de las vidrieras neorrománicas que de las neogóticas. El propio marco propicia esta estética, la densidad de los colores y la abundancia de la grisalla restan luminosidad $y$, de hecho, hay una ausencia total de los estereotipados y típicos recursos goticis- 
tas, como los doseletes o las enmarcaciones a base de arcos apuntados. Además, la abundancia de motivos vegetales fue muy frecuente en los vitrales que pretendían la filiación con el Románico, pues la inexistencia casi total de ejemplos medievales en los que basarse limitaba el repertorio iconográfico. Por último, la disposición concéntrica, simétrica y ordenada, rehúye de cualquier esbozo de verticalidad.

Como indicábamos con anterioridad, una de las novedades más interesantes del revival del vitral en los siglos XIX y XX fue la liberación de la temática únicamente religiosa, lo que le permitió tener un importante desarrollo en la arquitectura civil: en los edificios públicos, en las sedes de las instituciones y también, aunque de manera mucho más reducida, en las viviendas.

Por ello resultan sumamente interesantes las vidrieras que La Veneciana diseñó para la casa de Gabino Bobo. Este industrial, miembro de una de las sagas familiares más potentadas de Zamora, era propietario de una fábrica de harinas que había sido proyectada por el arquitecto Segundo Viloria en $1907^{44}$. En 1916 solicitó a este mismo técnico el diseño de su domicilio en

${ }^{44}$ Sobre este inmueble, vid., Á. ÁvILA DE LA TORRE, Op. cit., p. 154. Segundo Viloria Escarda, titulado en la Escuela de Arquitectura de Madrid, fue el técnico más importante de la arquitectura zamorana en el último cuarto del siglo XIX y uno de los grandes protagonistas de la misma en las dos primeras décadas del siguiente. Ocupó el cargo de arquitecto provincial durante cuarenta años, también fue arquitecto diocesano y responsable de varias obras promovidas por el Consistorio. Además de multitud de casas de vecindad y chalés -en Zamora y Benavente-, proyectó algunos de los edificios públicos más emblemáticos de la ciudad castellano-leonesa, como el Palacio Provincial (1878) o el Mercado de Abastos (1902). [A. VILORIA, Segundo Viloria (1855-1923). Un arquitecto zamorano, Zamora, 2007; J. C. de la MATA GuerRA, «Casa de doña Soledad González y su archivo familiar», Brigecio. Revista de Estudios de Benavente y sus tierras, 13, 2003, pp. 133-153 y Á. Ávila de LA TORRE, Op. cit., pp. 656-657]. un solar situado en el frente meridional de la plaza del Mercado. Es un inmueble eminentemente ecléctico, incluido dentro de su variante polícroma. Presenta algunos elementos habituales en el repertorio de ese facultativo, como el empleo de los nuevos materiales: el ladrillo, que dejó a la vista en las fachadas, y sobre todo el hierro de los antepechos de los balcones, que forman unos motivos circulares muy característicos en sus obras. Por otro lado, como era frecuente en la época, en consonancia con la libertad de la arquitectura del momento, hay pinceladas modernistas y sobre todo historicistas, más concretamente neomudéjares. Quedan patentes en los juegos de zigzag logrados con la disposición de las piezas aplantilladas en la fachada principal, en las ménsulas a base de rollos y en los arcos lobulados de la carpintería de los miradores ${ }^{45}$.

En el interior se conserva el portal y sobre todo la magnífica y efectista escalera volada dotada de una barandilla de exquisita forja que nace de un espléndido farol situado en la planta baja. Fue precisamente para los vanos de iluminación de su caja que el industrial encargó las vidrieras al taller aragonés. El motivo era evitar la oscuridad en esa parte de la casa, llenarla de una luz matizada y cálida y, empleando las palabras de Juan Bautista Lázaro al hablar de esta tipología, sustituir unos corrientes vidrios incoloros e inexpresivos, a través de los cuales no se ve más que las fealdades de un patio de vecinos ${ }^{46}$.

Hoy se conservan nueve vidrieras, las correspondientes a los vanos abiertos al patio de luces, pero por los planos realizados por Segundo Viloria parece que la idea original era colocarlas también en los muros laterales, para dar una mayor grandio-

\footnotetext{
45 Á. Ávila De La TORRe, Op. cit., p. 306.

${ }^{46}$ J. B. LÁZARO, Op. cit., p. 23.
} 
sidad a la escalera y dotar de luz a los pasillos. Confeccionadas en 1917, son de buena factura y tímida iconografía, reducida a un juego de variadas formas distribuidas a modo de marco, en realidad simplificaciones que parten de motivos neoplaterescos, realizadas con amarillo de plata y grisalla sobre un fondo monocromo a base de piezas rectangulares de vidrio. La disposición tridimensional de los diseños, que parecen una versión más sencilla de los de los vitrales que la casa zaragozana realizó para el Centro Mercantil de esa ciudad, la discreta presencia de otras tonalidades y la inclusión de flores, quizás interpretables como un guiño modernista, les confieren una cierta originalidad.

La elección de un lenguaje clasicista no es baladí, pues responde a múltiples razones. En primer lugar fue, junto con la modernista, la opción mayoritaria para las vidrieras civiles, piezas para las que no existían unos referentes históricos que reinventar. Por otro lado, la casa de Gabino Bobo era su domicilio y su oficina por lo que pareció conveniente que poseyera una cierta solemnidad, al modo de los edificios oficiales, en los que generalmente se optaba por esta estética. Por último, la preferencia por las formas neorrenacentistas respondía a la superación de las mudejarizantes como referentes de la arquitectura nacional que, a raíz del desastre del 98, comenzaron a verse como expresión de una sociedad folclórica y superficial ${ }^{47} \mathrm{y}$, por tanto, fueron relegadas como lenguaje atractivo para las construcciones.

De treinta años más tarde datan las vidrieras de la antigua sede de la Delegación Provincial de Abastecimientos de Zamora, inmueble proyectado en 1945 por el arquitecto Jesús Carrasco-Muñoz (1899-

\footnotetext{
${ }^{47}$ V. NieTO AlCAide, La vidriera..., Op. cit., p. 269.
}

1960, titulado en 1928) ${ }^{48}$. A pesar de compartir la austeridad y la difícil clasificación de una buena parte de la arquitectura de la Posguerra, el autor quiso dotarla de un aire grandilocuente. Así, singularizó los esquinales, dividió la fachada principal en tres calles, acusó en la zaguera la disposición arqueada de la escalera, incluyó claves molduradas y coronó los muros con una destacada cornisa. En el interior, hoy muy alterado, el patio de operaciones ocupaba el centro. La limpieza de líneas era su característica principal, pero como elemento decorativo se decidió proteger con vitrales tres amplios huecos del primer piso.

Técnica y estéticamente estas vidrieras corresponden a un momento muy posterior a los ejemplos anteriormente comentados. Los cristales son más grandes, los colores han perdido variedad cromática y el emplomado adquiere un gran protagonismo y se convierte en el definidor de los perfiles. Respecto a los temas, aparecen representadas tres vistas de las principales ciudades de la provincia, la Catedral de

48 AHPZa (Archivo Histórico Provincial de Zamora), FV (Fiscalía de la Vivienda), sign. 10/23. Jesús Carrasco-Muñoz Pérez-Isla trabajó principalmente en Madrid, su localidad natal, por ejemplo diseñó las casas de la calle Modesto Lafuente no 88 (1930-1935) y tres edificios para Pedro Párbole Gutiérrez y Francisco de la Cal en la avenida de las Islas Filipinas, que fueron comenzadas por él en 1935 y finalizadas por su padre, Jesús Carrasco Muñoz. Además fue el autor de los grupos de sendos grupos de viviendas obreras de la Obra Sindical del Hogar y de la Arquitectura en Valladolid (1937) y Zamora (1944). [Ó. DA RochA ARANDA y S. de TORRES NEIRA, Arquitectura madrileña. Del Eclecticismo a la Modernidad. Jesús Carrasco Muñoz (1869-1957), Madrid, 2002; A. BERLINCHES ACíN (dir.), Arquitectura de Madrid, Madrid, 2003; E. DE TERESA TRILLA, «Primeras experiencias de vivienda masiva en Valladolid: la aparición de un nuevo tipo residencial», en S. MATA PÉREZ, Arquitecturas en Valladolid. Tradición y modernidad (1900-1950), Valladolid, 1989, pp. 257-262; J. C. ARNUNCIO PAStOR, Guía de arquitectura de Valladolid, Valladolid, 1996, pp. 219-220 y Á. Ávila De LA ToRre, Arquitectura..., Op. cit., pp. 456-458]. 
Zamora con el río Duero y el barrio de Cabañales a sus pies, la Colegiata de Toro, con el detalle interesante de que el cimborrio aparece tal y como estaba antes de ser restaurado, y la torre del Caracol de Benavente, único vestigio que se conserva del antiguo Palacio de la Mota.

Responden a los criterios de la época, cuando la vidriera emplomada comenzaba a entrar en decadencia y su presencia en la arquitectura civil quedó reducida a las sedes gubernativas o de importantes corporaciones. Iconográficamente, concuerdan con

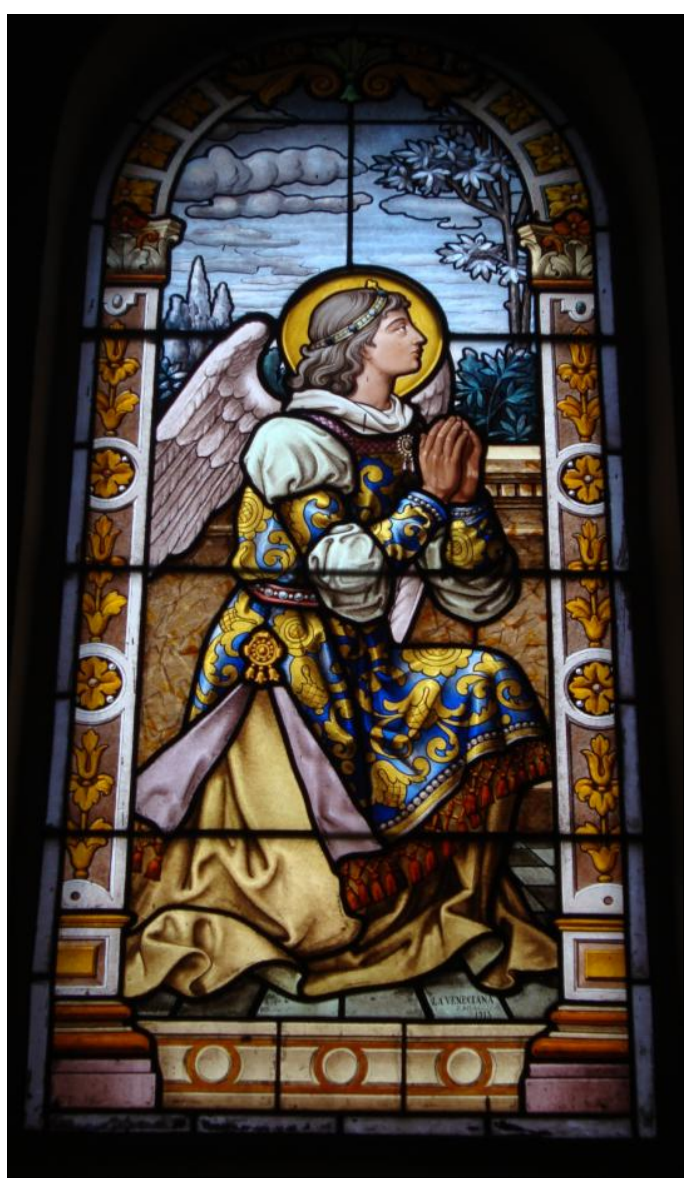

- Fig. 1. Vidriera de la tribuna de la Capilla de los Marqueses de Castellanos. Salamanca (1913) La Veneciana. la voluntad de ensalzar los territorios con visiones pintoresquistas de sus rincones más reconocidos. Ejemplos similares son el magnífico vitral de la Estación de Abando de Bilbao (1948), realizado por el taller Unión de Artistas Vidrieros de Irún $^{49}$ o los que decoran el zaguán de la sede de Heraldo de Aragón en Zaragoza, obra de los Mauméjean. En todos ellos se representaron monumentos característicos de sus respectivas provincias.

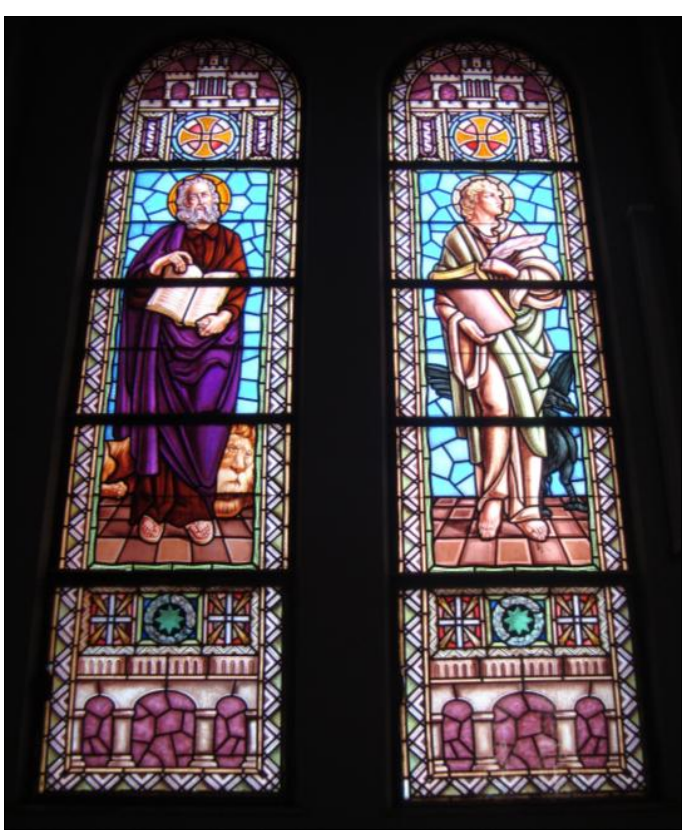

- Fig. 2. Vidriera de la Capilla del Hospital de los Montalvos. Salamanca (sin fecha) Atribuida a La Veneciana. San Marcos y San Juan.

-

${ }^{49}$ Esta compañía, fundada en 1923, realizó obras para multitud de localidades, como en los techos del Casino de Sevilla y del Hotel Carlton de Bilbao, en las catedrales de San Sebastián y Monzón (Huesca), en el Teatro Arriaga de la capital vizcaína y también en infinidad de ayuntamientos, restaurantes e iglesias en España, México y Estados Unidos. 


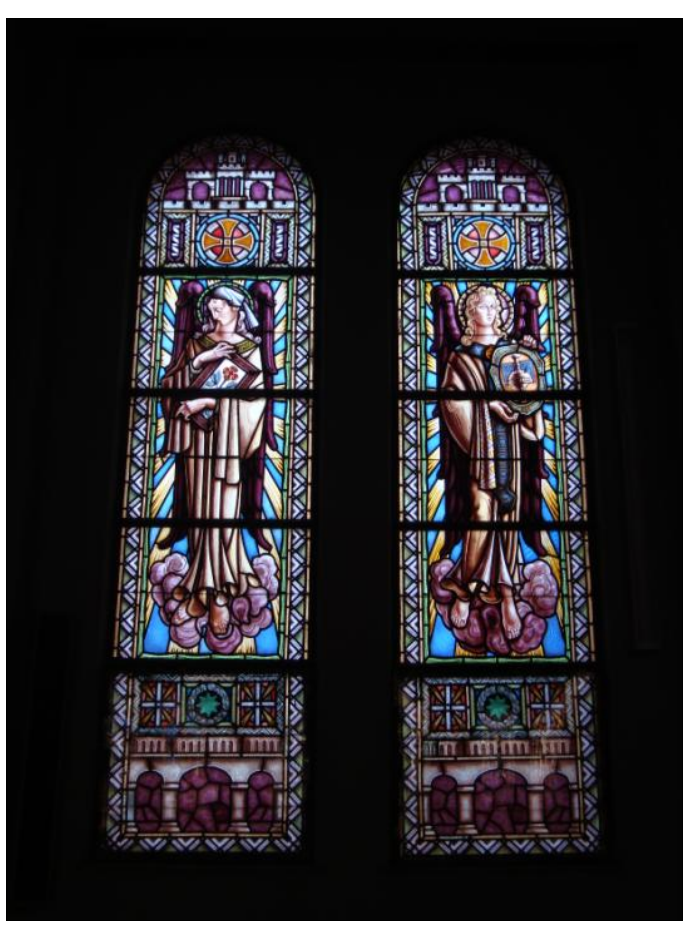

- Fig. 3. Vidriera del muro de la Epístola la Capilla del Hospital de los Montalvos. Salamanca (sin fecha) Atribuida a La Veneciana.

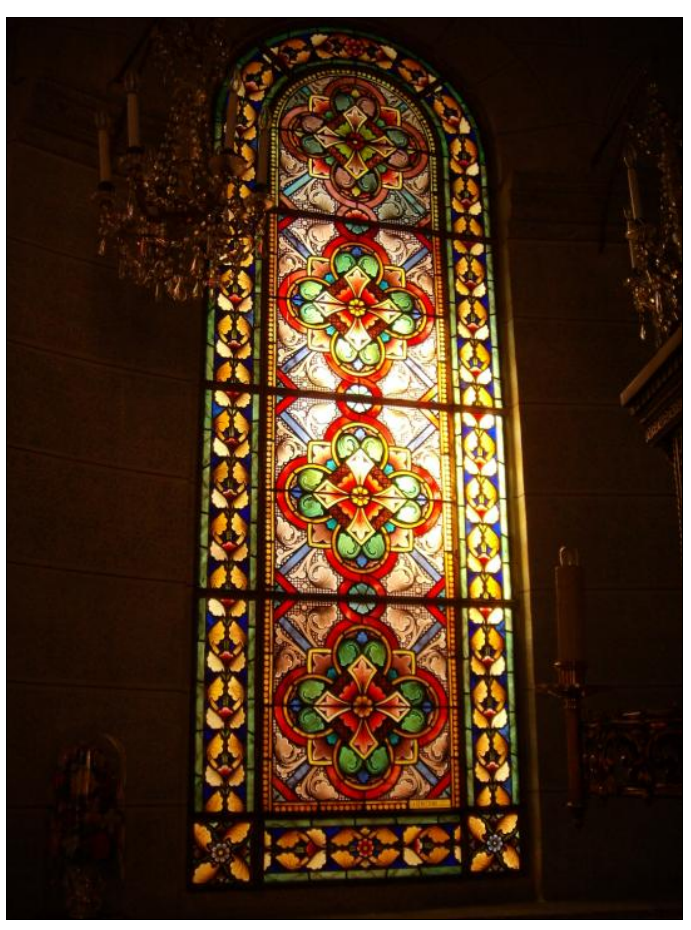

- Fig. 5. Vidriera de la cabecera de la iglesia del Corpus Christi. Zamora (1916) La Veneciana.

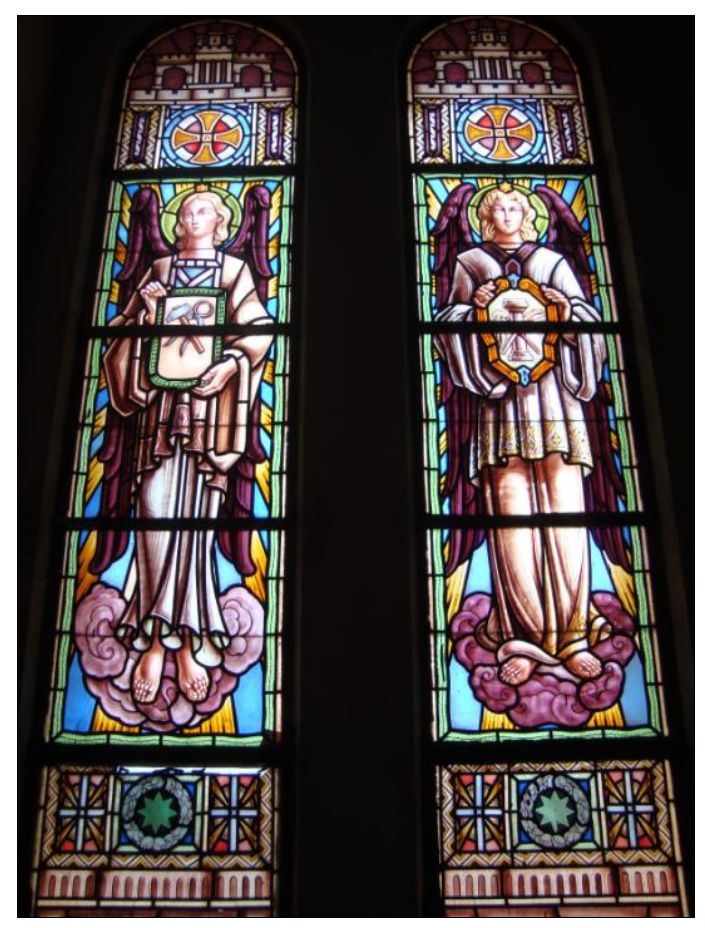

- Fig. 4. Vidriera de la sacristía de la Capilla del Hospital de los Montalvos. Salamanca ( $\sin$ fecha) Atribuida a La Veneciana.

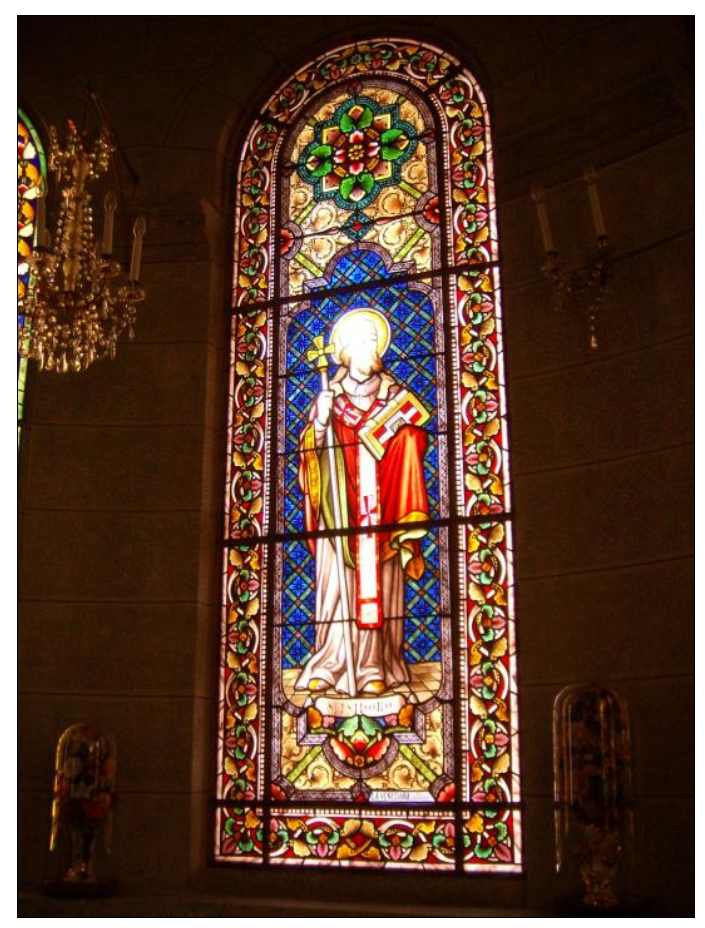

- Fig. 6. Vidriera de la cabecera de la iglesia del Corpus Christi. Zamora (1916) La Veneciana. San Isidoro. 


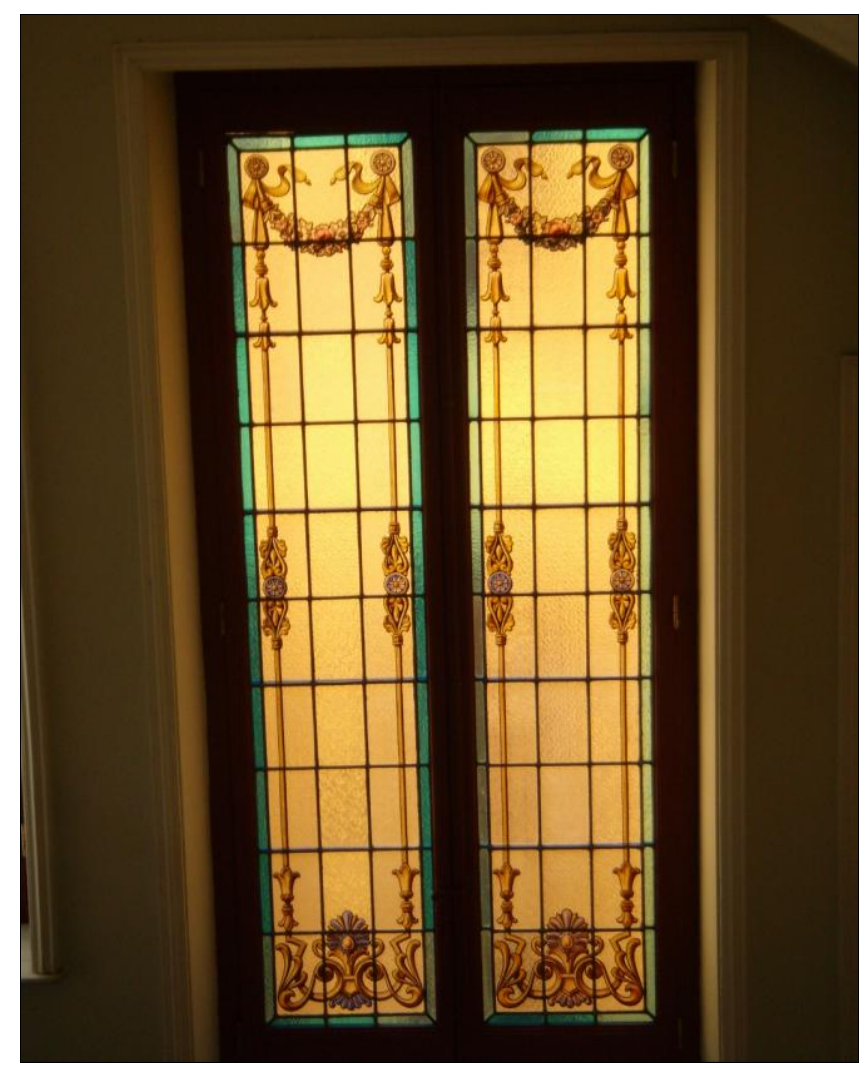

- Fig. 7. Vidriera de la escalera de la Casa Bobo. Zamora (1916) La Veneciana.

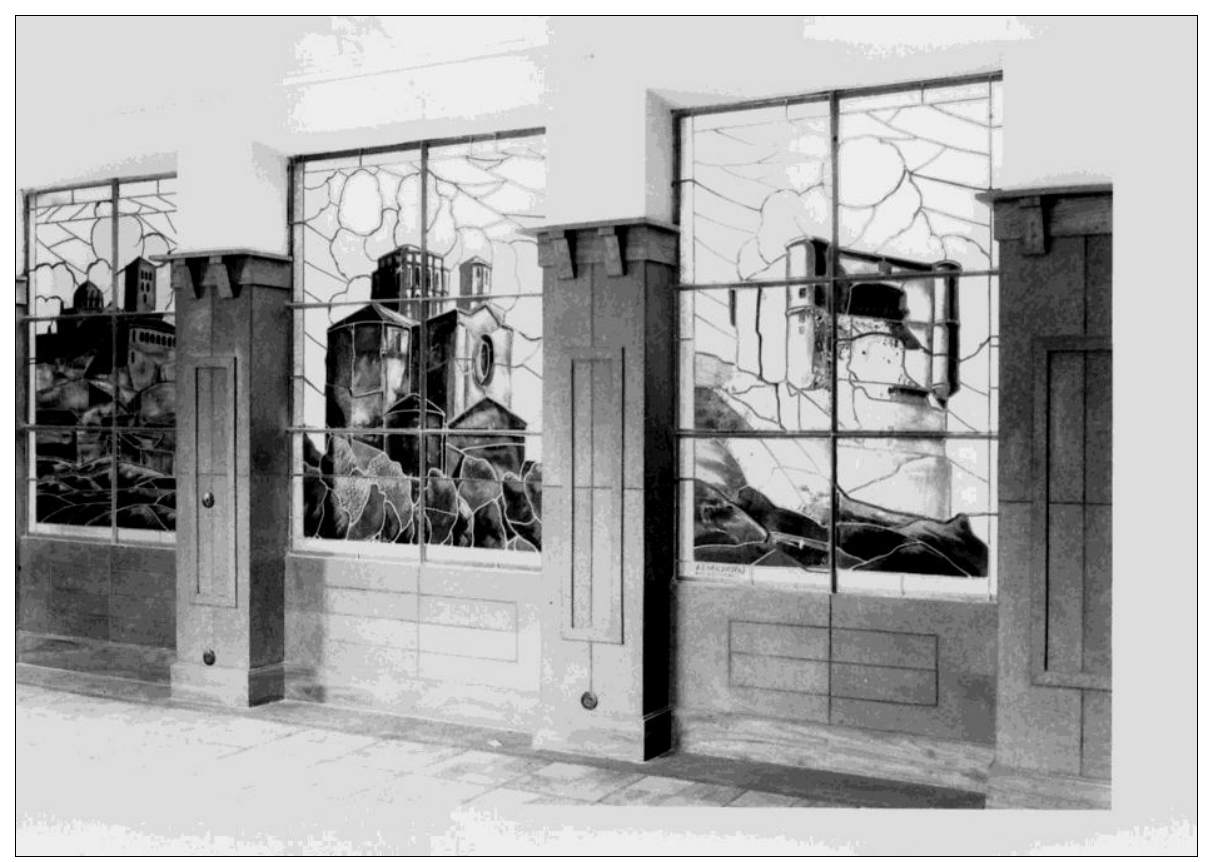

- Fig. 8. Vidrieras de la Delegación Provincial de Abastecimientos. Zamora (1945) La Veneciana. Foto del Archivo Gullón. 